\title{
Research on the Inheritance and Protection of Chinese Folk Art
}

\author{
Tang Haiyan ${ }^{1}$ \\ ${ }^{1}$ Changsha Normal University, Changsha, Hunan, 410100
}

Keywords: Chinese folk art; heritance; protection

\begin{abstract}
Under the background of new era, the inheritance and development status of Chinese folk art is not optimistic because of the influence of language environment, cultural background and economy. The inheritance and protection of Chinese folk art has become a hot topic, a wide range of people concerned, and relevant experts and scholars have also started to analyze and research. This paper aims at many problems that arise in the inheritance and development of Chinese folk art, and puts forward some relevant inheritance and protection strategies in the hope of providing reference for the inheritance and protection of folk art in our country.
\end{abstract}

\section{Introduction}

Chinese folk art is a unique form of art formed by folk oral literature and singing art after long-term development. At present, there are over 400 kinds of art forms of folk art circulated in China. Each form of folk art has its own course of development and artistic features, one of the most popular, but also based on the masses is the rap-based art form. For example, comments, storytelling, comic dialogue, the Northeast drums, Beijing rhyme drums, Hubei bass, allegro, Pingxiang spring gongs, money plates in Shandong and Anhui Qinshu, Yunnan dulcimer, Ningbo walk books, two biography, Fengyang hub and so on [1]. Under the background of the new era, the Chinese folk art has the historic opportunity as well as some challenges. The reason is that the language environment is increasingly complicated in the new era. At some level, it restricts the art of Chinese folk art and receives foreign cultures. The Chinese folk art in the country less and less mass base, which led to the Chinese folk art in the country's heritage protection has been greatly hampered. Therefore, to strengthen the study of the inheritance and protection of Chinese folk art has important practical significance.

\section{The Status and Cause Analysis of Heritance and Protection of Chinese Folk Art}

\subsection{The status of the inheritance and protection of Chinese folk art}

As early as the 17th year of Emperor Kangxi, Chinese people began to use folk art to express their inner feelings, and gradually introduced various folk activities. Later, during the Qing Dynasty, the art of folk art in our country got an unprecedented development [1]. Since then, since the reform and opening up, after the implementation of the local reform policy in our country, a large number of pop music with popular colors are flooded with the domestic music market. This has had a relatively strong impact on the art of Chinese folk art and the art of Chinese folk art has gradually fallen into a downturn. Only a few local folk art such as Cantonese opera retains a certain mass base. Later, with the continuous improvement of domestic social and economic level, the art of folk art in our country continued to be innovated. Through the construction of the regiment, the production of repertory, personnel training and the renovation of folk art, it was tried to promote the inheritance of folk art in our country. However, under the background of a sharp decline in the domestic art market, these solutions seem insignificant and can not fundamentally achieve the protection of Chinese folk art. So what are the problems in the process of the inheritance and protection of folk art in our country? The following part of a specific discussion.

First of all, some folk art audiences are small in size and have a poor generalization. Chinese folk art has not yet had a very wide mass base. Especially with the popularization of various popular music and folk art forms, a large number of people have locked their eyes on the more colorful and 
varied forms of folk art, which led to the disappearance of a small part of Chinese folk art. Even though many Chinese folk art now have some symbolic meanings, the real people who love Chinese folk art are very few.

Second, there is a fault in the inheritance of folk art. At present, with the passing away of the older generation of folk artists, most young people are fascinated by the current pop music and are not willing to spend time and energy on learning Chinese folk arts. This is very detrimental to the inheritance and protection of folk arts in China. In particular, as the age of the famous song and dance artists grows, their performance on the stage has subsided. Even if a small number of young people really love Chinese folk art, it is very difficult to absorb them well in a way known to famous song and dance artists Qu arts art essence [2]. This led to our country's outstanding number of folk art inheritors showed a downward trend year by year, high-quality talent is even more rare and precious folk art. In general, there is a faulty phenomenon in the inheritance and protection of folk art in our country.

Finally, the number of folk art lovers plummeted. With the current pop music, comic dialogue, jazz and other forms of music is constantly enriched in most of our cities, especially in the more economically developed first-tier cities such as Beijing, Shanghai, Guangzhou, more young people and some of the number of People in the world have become more and more interested in these pop music with rich flavor of the times [2]. Few people learn or appreciate Chinese folk art, which makes the number of folk art lovers in China decrease year by year. In the meantime, all news media in our country are also pursuing the largest audience ratings to cater to the tastes of the general public. As much as possible, popularized pop music popular in the programs has also led to a more outdated piece of folk art in our country. There is no self- Communication channels. The current situation is that for many post-90s or post-zero-time period, they hardly knew about the art form of Chinese folk art and even if they knew it, they only knew a bit about it.

\subsection{The reasons for the status of the inheritance and protection of Chinese folk art}

First of all, multimedia has greatly influenced the Chinese folk art. Since the eighties of last century, China has implemented the policy of reform and opening up its coastal cities and implemented the policy of "giving prosperity first and boosting the prosperity of the rest of the world so as to promote common prosperity." Under such a background, China has stepped up trade with western countries. Among them, the western culture has gradually entered the field of vision of the people, deeply affecting people's way of life. International films represented by European and American films have aroused strong interest in the country and enriched people's daily life. Subsequently, under the background of continuous improvement of the national economy, people's standard of living is also getting higher and higher, with material needs and spiritual needs also increasing. Electrical equipment represented by televisions and audio tape recorders provide a brand new way of relaxation. People can stay at home to achieve the purpose of watching movies. Later, the advent of tapes and tape recorders provided people with a cheaper way of viewing movies. People could directly copy programs to watch the programs and greatly reduce the economic costs. This led to the downturn in the art of folk art in our country. In addition, television programs are gradually introduced, many folk art was moved to the TV screen to play, which to some extent, also affected the development of China's folk art market.[3] Today, in the context of the Internet, the colorful cyberworld gives people a whole new way of enjoying themselves, allowing people to perform precise web searches to their liking to find their favorite entertainment, such as singing $\mathrm{K}$ software, dancing Software and various kinds of game software, etc., all affect the inheritance and protection of Chinese folk art from some aspects, which makes the development of Chinese folk art face severe challenges.

Second, the form of folk art is out of step with the times. At present, the form of folk art in our country still retains the traditional form of folk art, which leads our country folk art to fail to integrate with the modern multiple stage in the programming and protection of the programs. It lacks certain contemporary flavor and can not satisfy the present People's growing spiritual and cultural needs, and people's aesthetic taste out of touch. In addition, as the number of Chinese folk 
art inheritors declines year by year, the majority of folk artists who appear on the large stage in China are mostly older actors who do not possess a large mass base and who do not have a modern stage performance, and the development of the times are out of touch.

Lastly, popularization of Putonghua. At present, with the popularization of Mandarin in our country, the art of folk art in many places has been seriously threatened. For example, most Cantonese opera is mainly in Cantonese, while the performers often use Cantonese dialects as well. Cantonese is different from Putonghua in both pronunciation and reading. The people in the northern cities of China and the Central Plains can not understand Cantonese basically. However, influenced by the popularization of Putonghua, the Cantonese opera is gradually restricted by the language environment, which makes the inheritance and protection of some local folk art more difficult [3].

\section{The Strategy Analysis of Heritance and Protection of Chinese Folk Art}

First of all, combining traditional art forms with a variety of art forms. Despite its long history, the art of folk art in our country still needs to keep pace with the times in the process of concrete inheritance and protection and constantly innovate its contents. Through the integration of other diversified art forms to continuously enrich the contents of folk art in our country, the art of Chinese folk art is made modern [4].

\subsection{To create a new art show}

In our art of folk art, most of them reflect the traditional feudal thought and choose the contemporary artistic theme, which has great differences with the rapid development of our country's economic status quo. It also needs to constantly update the theme of art, making the art of Chinese folk art also Keep up with the pace of development of the times and create the contents of folk art in line with the needs of the times to meet the rapidly growing economic needs of the people.

\subsection{To create the performer creative training}

Due to the limited number of successors of folk art in our country, the number of people who voluntarily learn Chinese folk art is extremely limited. Therefore, there is an urgent need to innovate the training model of folk art actors and to attach importance to the recruitment and cultivation of folk art under the innovative model. For example, a province in our country uses Quyi to enter the campus. This course adds Quyi to the pupils' routine learning courses. This greatly saves the cursory excuse to learn art from the Quyi artists, and also promotes the promotion of folk art the goal of. The influence of primary school pupils on Chinese folk art from an early age can help cultivate their interest and interest in folk art. This has laid a solid foundation for the inheritance and protection of Chinese folk art.

\subsection{To combine modern pop music and technology}

The single Chinese folk art is not yet attractive enough. The integration of popular music and advanced science and technology in Chinese folk art can enrich the artistic forms and performance characteristics of Chinese folk art, so as to infuse new art into Chinese folk art. Vitality, enhance the charm of Chinese folk art, and more contribute to its own heritage and protection.

Secondly, the inheritance and application of new media forms. Nowadays, with the continuous progress of science and technology, the advanced science and technology represented by network technology, computer technology and information and communication technology have made great progress. Under the background of information age, the art of Chinese folk art also needs to be combined with modern multimedia technology. The promotion and promotion of folk art in our country is conducive to the popularization of Chinese folk art throughout the country. This will enable experts, talents and scholars interested in folk art from all walks of life to provide the inheritance and protection of Chinese folk art. A certain amount of help, we can make full use of online media, television media and self-media and other forms, to increase the packaging of 
Chinese folk art, so that Chinese folk art is generally loved by people, and then into the tens of thousands of households.

Finally, public welfare activities vigorously carried out. In order to increase the inheritance and protection of Chinese folk art, we can adopt the method of public welfare activities and join hands with a number of television stations to promote and disseminate Chinese folk art. For example, in June 2016, Guangdong Quyi Art Association and a number of television stations jointly established the "Guangdong Qu Folk Art Belt One Belt" public welfare activities, which not only reflected the combination with the development of the times, but also contributed to the inheritance and development of Chinese folk art and public welfare activities. [5] The vigorous development will provide people with delicious spiritual food. At the same time, it also enhances the popularity of Chinese folk art in the country. It can be said that it is a matter of multiplying things with less effort.

\section{Conclusion}

This article first analyzes the status of the inheritance and protection of Chinese folk art, then discusses the reasons of the existing problems in the inheritance and protection of Chinese folk art, and finally puts forward the related strategies of the inheritance and protection of Chinese folk art. It is hoped that this study can actively solve the problems of China. The problems in the inheritance and protection of folk art and the promotion of the Chinese folk art in the positive direction. In the new era background, the inheritance and protection of Chinese folk art have both new historical opportunities and great challenges. The inheritance and protection of Chinese folk art also need to be studied and discussed in depth. Due to my limited knowledge, exposition inevitably there are some deficiencies, but also hope that the relevant experts and scholars can give criticism and correction.

\section{References}

[1] Li Hong, Liu Jian.Study on the Inheritance and Development of Tourism Industrialization of Local Folk Songs in Shandong Province [J]. China Business Studies, 2017 (5): 117-119.

[2] Chen Jinrong. New Exploration of Carrying Forward Traditional Folk Art - On the "One Belt, One" Charity Activities of Folk Songs in Guangdong [J]. 2017 (4): 36-37.

[3] Qiao Qiqi, Zhao Lingjie, Ma Yu. New Media Creative Inheritance of Local Folk Art - A Case Study of Cangzhou Wood Bass [J]. New Media Research, 2017, 3 (2): 35-36.

[4] Li Yi. On Chinese minority art in primary and secondary education and heritage [J]. Art Evaluation, 2017 (2): 141-143.

[5] Ja Leilei. The Forum for the Excellence of Chinese Culture and Art Inheritance and Development - Intertextuality of Chinese Excellent Traditional Culture [J]. Art Commentary, 2017 (10): 6-14. 